\title{
Investigating the Mechanical and Durability Performance of Cement Mortar Incorporated Modified Fly Ash and Ground Granulated Blast Furnace Slag as Cement Replacement Materials
}

\author{
Ali Abdulhussein Shubbar ${ }^{1}$, Dhiya Al-Jumeily ${ }^{2}$, Ahmed J. Aljaaf ${ }^{2,3}$, Mohammed Alyafei ${ }^{1}$, Monower Sadique ${ }^{1}$, and Jamila Mustafina ${ }^{4}$ \\ ${ }^{1}$ Department of Civil Engineering, Liverpool John Moores University - UK \\ ${ }^{2}$ Department of Computer Science, Liverpool John Moores University - UK \\ ${ }^{3}$ Center of Computer, University of Anbar - Iraq \\ ${ }^{4}$ Kazan Federal University, Kazan - Russia \\ A.A.Shubbar@2014.ljmu.ac.uk, D.Aljumeily@ljmu.ac.uk, A.J.Aljaaf@uoanbar.edu.iq, \\ M.A.Alyafei@2016.1jmu.ac.uk, M.M.Sadique@1jmu.ac.uk, DNMustafina@kpfu.ru
}

\begin{abstract}
The process of cement manufacturing produces a huge amount of carbon dioxide (CO2). The utilization of alternative waste materials from various industrial processes as a partial substitution to cement is encouraged due to environmental and specific technical requirements. This strategy will have the potential to reduce cost of cement, conserve energy, and reduce waste volumes. Therefore, the aim of this research is to investigate effect of the replacement of cement with modified fly ash (MFA) and ground granulated blast furnace slag (GGBS) to reach $80 \%$ total replacement on mechanical and durability performance of cement mortar. Normal consistency, the initial and final setting times, compressive strength and electrical resistivity of all the ternary mixtures were determined and compared with the control binder. Compressive strength and electrical resistivity were tested at various curing ages of $3,7,14$, and 28 days. Test results revealed that the normal consistency of the ternary mixtures increased with increasing the GGBS and MFA content, while the initial and final setting time decreased compared to that of control mixture. The results also showed that the compressive strength of all the ternary blends mortars were lower at early and later ages in comparison with control mortar. The reductions in the compressive strengths of the ternary mixtures $\mathrm{T} 40, \mathrm{~T} 60$ and $\mathrm{T80}$ compared to the control mixture were approximately $16 \%, 29 \%$ and $37 \%$, respectively at 28 days. The surface electrical resistivity of ternary blends mixtures was higher than the control mixture at all curing ages. The use of GGBS and MFA in the production of cement mortar and concrete can significantly help in reducing the $\mathrm{CO}_{2}$ emissions of the cement industry and reduce the overall cost of cement.
\end{abstract}

Keywords-GGBS; MFA; cement replacement; compressive strength; electrical resistivity.

\section{INTRODUCTION}

Ordinary Portland cement (OPC) is the most common traditional construction material that is used as a binder substance in different civil engineering projects worldwide $[1,2]$. However, there is no doubt that the cement industry has a negative environmental impact due to the emission of Carbon dioxide $\left(\mathrm{CO}_{2}\right)$ which contributes to the phenomenon called greenhouse gasses (GHG) [3-5]. It has been reported by many researchers that cement industry is energy intensive with approximately $15 \%$ of global energy consumption. Moreover, it consumes 1.5 tonne of raw materials and produces about 1 tonne of $\mathrm{CO}_{2}$ emission for each single tonne of manufactured cement [6-8].

Therefore, looking for alternative materials to cement has become a vital issue to reduce the damage caused by the cement industry. By-products or waste materials can be promising alternatives to cement for production of new binders for the use in different applications in civil engineering projects.

Huge quantities of wastes and industrial by-product are resulted from different industrial sectors globally. These materials represent another environmental issue due to the costs of transporting, lake of lands for depositing and the leakage of potential hazardous compounds that may be available within the chemical compositions of the byproducts [2]. Therefore, in order to overcome this problem, the reuse of such materials as cement replacement can contribute in both the depositing issue of such materials as well as to reduce the use of cement, which reflects a reduction of cement manufacturing impact [7].

Although the use of a combination of fly ash (FA) and ground granulated blast furnace slag (GGBS) as cement replacement has been extensively investigated in numerous research articles, however, the use of a combination of modified fly ash (MFA) and GGBS as cement replacement material is a novel approach. Therefore, this paper presents the results of experimental work to investigate the mechanical and durability performance of cement mortar incorporated MFA and GGBS as cement replacement materials. 


\section{MATERIALS}

\section{A. Sand}

Building sand passing from sieve size $3.35 \mathrm{~mm}$ was used to prepare the mortar samples. This type of sand is identified in the British standard BS EN 196-1[11]. The particle size distribution of the sand is presented in figure 1 .

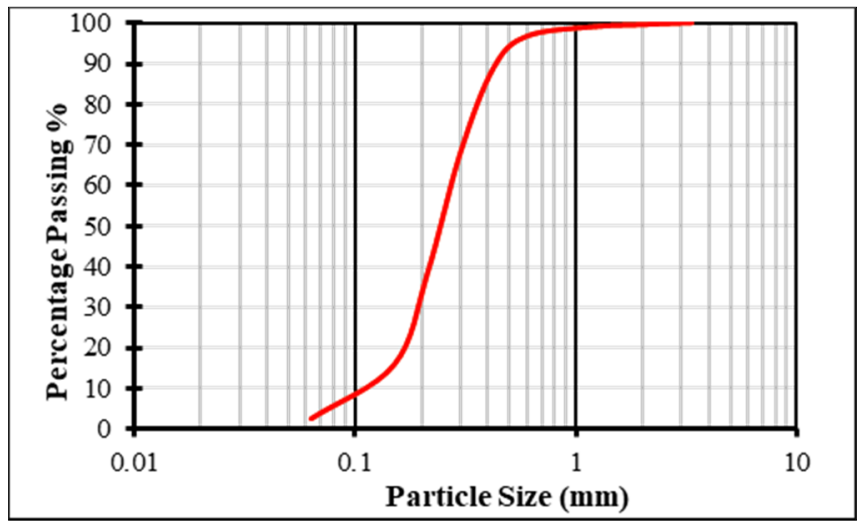

Fig. 1. Particle size distribution of the sand.

\section{B. Water}

Tap water was used in this study to prepare all samples tested in this study.

\section{Binder materials}

Ordinary Portland cement (OPC), modified fly ash (MFA) and ground granulated blast furnace slag (GGBS) were used as binder materials in the production of cement mortar. The cement used in this study was OPC type CEMII/A/LL 32.5-N and it was supplied by the CEMEX Quality Department, Warwickshire, UK. The GGBS was provided by the Hanson Heidelberg Cement Group, Scunthorpe, UK. The MFA is FA that mixed with a combination of supplementary hydraulic cementitious materials. The MFA was supplied by Cenin Ltd, Bridgend, UK.

The chemical compositions of OPC, GGBS and MFA were determined using the X-Ray fluorescence (XRF) analysis type Shimadzu EDX-720. The results obtained from this test are listed in Table I. Regarding the classification of MFA, the $\mathrm{CaO}$ content in MFA (32.86\%) makes it be classified as a fly ash class $\mathrm{C}$ according to the British Standard BS EN 450:1995 [12]. Fly ashes class C has sufficient $\mathrm{CaO}$ content, which can exhibit a hardening property without cement when they are added to the water [10]. Regarding to GGBS, it has a significant proportions of most principle oxides ( $\mathrm{Ca}, \mathrm{Si}, \mathrm{Mg}$ and $\mathrm{Al}$ ) and its $\left(\mathrm{CaO}+\mathrm{MgO} / \mathrm{SiO}_{2}\right)$ is more than 1.0 which is agrees with $\mathrm{BS}$ EN 197-1:2000 requirements for granulated blast furnace slag [14].

The particle size distribution (PSD) and specific surface area (SSA) are important physical tests that provided information about the fineness of the binder materials. Figure 2 shows the PSD of the OPC, GGBS and MFA as obtained from the laser particle size analyser.
TABLE I. CHEMICAL COMPOSITION OF OPC, GGBS AND MFA

\begin{tabular}{|c|c|c|c|}
\hline Item & OPC & GGBS & MFA \\
\hline $\mathrm{CaO}^{2}$ & 65.21 & 42.51 & 32.86 \\
\hline $\mathrm{SiO}_{2} \%$ & 24.56 & 41.06 & 43.77 \\
\hline $\mathrm{Al}_{2} \mathrm{O}_{3} \%$ & 1.70 & 5.12 & 4.94 \\
\hline $\mathrm{Fe}_{2} \mathrm{O}_{3} \%$ & 1.64 & - & 6.96 \\
\hline $\mathrm{MgO} \%$ & 1.30 & 4.25 & 4.91 \\
\hline $\mathrm{Na}_{2} \mathrm{O} \%$ & 1.34 & 3.09 & 2.92 \\
\hline $\mathrm{K}_{2} \mathrm{O} \%$ & 0.82 & 0.69 & 2.26 \\
\hline $\mathrm{SO}_{3} \%$ & 2.62 & 1.27 & 1.30 \\
\hline $\mathrm{TiO}_{2} \%$ & - & 0.98 & 0.08 \\
\hline $\mathrm{LOI}^{\circ}$ & 0.28 & 0.37 & 2.41 \\
\hline $\mathrm{pH}$ & 12.73 & 11.02 & 10.68 \\
\hline Specific Gravity & 2.94 & 3.05 & 2.71 \\
\hline
\end{tabular}

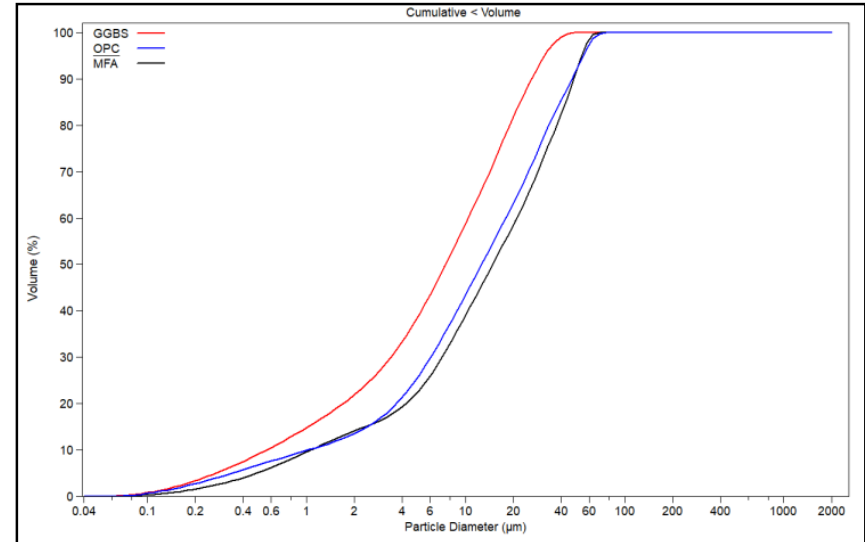

Fig. 2. Cumulative particle size distribution of OPC, GGBS and MFA.

Additionally, Table 4.2 shows the differences in $\mathrm{d} 50$, median and SSA for the OPC, GGBS and MFA.

TABLE II. DIFFERENT IN $D_{50}$, MEDIAN AND SSA OF THE BINDER MATERIALS

\begin{tabular}{|c|c|c|c|}
\hline Mix Id & OPC (\%) & GGBS (\%) & MFA (\%) \\
\hline $\mathrm{d}_{50}(\mu \mathrm{m})$ & 9.43 & 5.40 & 10.68 \\
\hline Median $(\mu \mathrm{m})$ & 12.66 & 7.52 & 14.84 \\
\hline Blain SSA $\left(\mathrm{cm}_{2} / \mathrm{g}\right)$ & 4296 & 6931 & 4645 \\
\hline
\end{tabular}

The PSD and SSA of the binder materials (OPC, GGBS and MFA) have a significant effect on the compressive strength of the mortar and concrete. The finer the particles of the material used as partial replacement to cement in mortar and concrete production, the higher the compressive strength obtained $[15,16]$. It can be seen from the particle size distribution chart in figure 2 that GGBS has finer particles relative to the other materials. This means that the GGBS has a higher pozzolanic reactivity than the other materials as it has a higher SSA $[1,17]$. 


\section{Methodology}

\section{A. Mixing proportions}

Three different ternary mixtures prepared from mixing OPC, GGBS and MFA using different proportion in addition to the reference binder $(100 \%$ OPC) was considered in this study as illustrated in Table III. The water to binder (W/B) and the sand to binder $(\mathrm{S} / \mathrm{B})$ ratios were maintained constant as 0.4 and $1: 2.5$, respectively for all mortar mixtures.

TABLE III. MIXING PROPORTION OF THE TERNARY MIXTURES

\begin{tabular}{|c|c|c|c|}
\hline Mix Id & OPC (\%) & GGBS (\%) & MFA (\%) \\
\hline Control & 100 & 0 & 0 \\
\hline T40 & 60 & 20 & 20 \\
\hline T60 & 40 & 30 & 30 \\
\hline T80 & 20 & 40 & 40 \\
\hline
\end{tabular}

\section{B. Samples' preparation}

After weighing the required weight of sand and binder, the materials were mixed using Hobart N50-110 mixer for 5 minutes. After that, a tap water was added and another mixing process for 5 minutes was applied to form the cement mortar. For the samples of the compression strength test, the mortars were casted in moulds with dimensions of $40 \mathrm{X} 40 \mathrm{X}$ $160 \mathrm{~mm}$ while for the electrical resistivity test; the mortars were casted in cylindrical moulds with diameter of $100 \mathrm{~mm}$ and height of $200 \mathrm{~mm}$.

Regarding the curing conditions, the samples tested for compressive strength and electrical resistivity tests were subjected to a wide range of curing period covered the short periods ( 3 and 7 days) and later curing periods (14 and 28 days) in order to investigate the effect of curing time on the evolution of the compressive strength and electrical resistivity. The samples were cured at the ambient temperature and were kept in a plastic tank filled with a tap water until reach the designed age of curing.

\section{Testing programme}

The experiment utilised in this study comprised the physical, mechanical and durability properties of the paste and mortars prepared using binders produced from OPC replaced with GGBS and MFA at different percentages.

\section{Consistency and Setting Times}

The consistency test depends mainly on the water to binder ratio, fineness and rate of hydration reactions of the binder [18]. By using the Vicat apparatus, the consistency test was done first on paste samples prepared from OPC replaced with the GGBS and MFA at different percentages. This test was conducted to evaluate the best water/binder ratio for each prepared mixture. This ratio is very important; it is required to prepare the paste, and mortar samples for other experiments. After the identification of the optimum water/binder ratio, the determination of hardening times (initial and final setting times) was carried out using the same apparatus (Vicat). According to Naik et al. [19], the test of setting times helps to get indications about the hardening properties and the availability of sufficient hardness of the binder. The test of the consistency and setting times was carried out in accordance with BS EN 196-3[20]

\section{E. Compressive strength}

Compressive strength testing was conducted to assess the mechanical performance of the cement mortars according to BS EN 196-1[21]. Three samples of dimensions 40 x $40 \mathrm{x}$ $160 \mathrm{~mm}$ were prepared for each mixing proportion and the test was conducted after 3, 7, 14 and 28 days of curing.

\section{F. Electrical resistivity}

One of the most important features of concrete is the long-term performance against the up normal or severe conditions. This performance is known as the durability. Since the electrical resistivity of the concrete plays a very big role in predicting the corrosion of the reinforced concrete [22], this test was utilised in this study. A Resipod Proceq meter was used to perform this test. The electrical resistivity was measured in accordance with AASHTO T358 [23]. This test is directly connected to the possibility of corrosion of concrete and mortar due to the diffusion of chloride $[18,24]$. Three cylinders with a diameter of $100 \mathrm{~mm}$ and a height of $200 \mathrm{~mm}$ were prepared and tested after 3, 7, 14 and 28 of curing. The readings were obtained 8 times for each specimen and the averages of 24 readings were taken to represent the final values for electrical resistivity.

\section{RESUlTS AND DISCUSSION}

\section{A. Consistency and setting time}

Table IV illustrates the measured consistency and setting times (initial and final) of the pastes prepared from binders produced from OPC, GGBS and MFA used in this study with different percentages of OPC replacement. The corresponding results of the consistency and setting times of the control binder (OPC) are also listed in Table IV for the purpose of comparison. Table IV shows that the consistency of control mixture and ternary mix with $20 \%$ MFA and $20 \%$ GGBS replacement levels (T40) is $33 \%$, while that of the ternary mixtures containing $30 \%$ and $40 \%$ of MFA and GGBS replacement levels (T60 and T80) shows increased values.

The consistency of the ternary mixtures contained (MFA+GGBS) varies between $33 \%$ and $35 \%$, depending on ground conditions of binder materials. The increased values in the consistencies of ternary mixtures (T40 and T60) are due to high fineness and the high SSA of MFA and GGBS particles $[18,25,26]$. Generally, waste and/or by-product materials require more amount of water to get desire consistency, which has been reported in previous studies [26, 27].

TABLE IV. RESULTS OF CONSISTENCY AND SETTING TIMES TESTS

\begin{tabular}{|c|c|c|c|}
\hline Mix Id & Consistency \% & $\begin{array}{c}\text { Initial setting time } \\
\text { (min) }\end{array}$ & $\begin{array}{c}\text { Final setting time } \\
\text { (min) }\end{array}$ \\
\hline Control & $33 \%$ & 275 & 292 \\
\hline T40 & $33 \%$ & 261 & 285 \\
\hline T60 & $35 \%$ & 225 & 243 \\
\hline T80 & $35 \%$ & 172 & 186 \\
\hline
\end{tabular}

The initial and final setting time of control and ternary mixtures are presented in the Table IV. The results shows that ternary binders tend to reduce the initial and final setting time of mortar compared to control mixture. The reduction in the initial and final setting time was increased with 
increasing the percentages of replacement of cement with GGBS+MFA. This reduction is mainly attributed to the presence of binder materials with high SSA (MFA and GGBS) that reduces the amount of free water available in the mixture. These results are generally consistent with previous findings by Sadique et al. [26] and Salih et al. [28]

\section{B. Compressive strength}

The compressive strength is the most important design parameter for any type of concrete structures. In this regard, strength development of mortars made with OPC, GGBS and MFA for various ages of curing are presented in figure 3 .

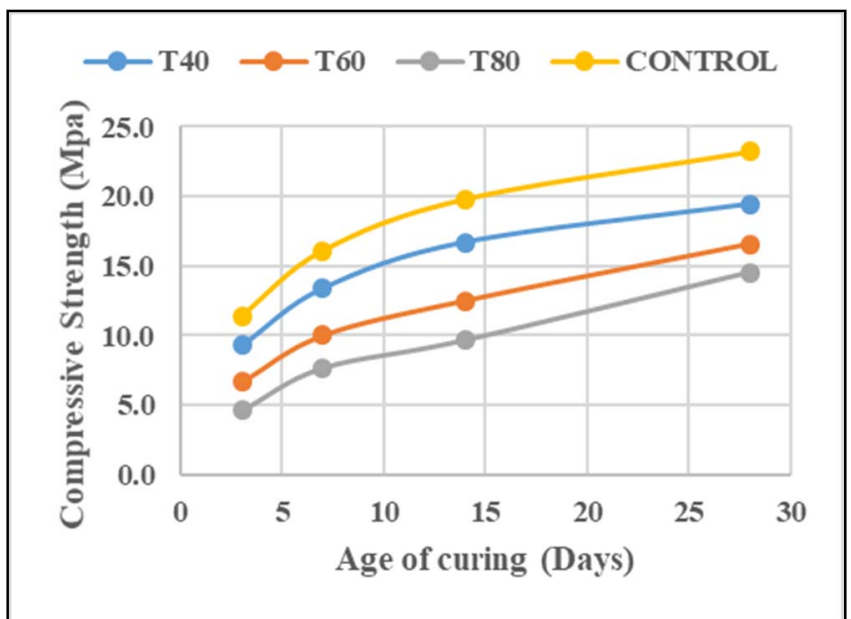

Fig. 3. Compressive strength development of different ternary blends at different ages

As expected, the strength of all mixtures increases continuously with time. It obvious from figure 3 that all the ternary blended mortars containing (MFA+GGBS) exhibited lower strength from 3 days onwards with increased the replacement levels in comparison with the control mixture.

At the age of 3 days, the mixtures T40, T60 and T80 have showed about $82 \%, 58 \%$ and $41 \%$ of the compressive strength of the control mixture. Increasing the age of curing to 7 days resulted in improvement in the compressive strength of the ternary mixtures relative to the control mixture. The 7 days compressive strength of T40, T60 and T80 were $83 \%, 62 \%$ and $48 \%$, respectively in comparison with the control mixture. This reduction in the compressive strength during the first week with increasing the percentages of GGBS and MFA could be attributed to the slow acquisition of strength for mixtures with high volume of GGBS and MFA at initial curing ages [18, 29, 30].

After 14 days of curing, the compressive strength of all the ternary mixtures have been improved by about $25 \%$ relative to that at the age of 7 days, while the improvement in the control mixture was about $23 \%$. Additionally, the mixtures T40, T60 and T80 have provided about $84 \%, 63 \%$ and $49 \%$ of the compressive strength of the control mixture, respectively.

At the age of 28 days, the compressive strength of the ternary mixture T40 was $19.4 \mathrm{MPa}$ that is about $84 \%$ of the compressive strength of the control mixture $(23.2 \mathrm{MPa})$ with improvement of $16 \%$ relative to the 14 days compressive strength. For the ternary mixtures (T60 and T80) there was a significant improvement in the compressive strength after 28 days relative to that at the age of 14 days with about $132 \%$ and $150 \%$, respectively. However, the ternary mixtures T60 and T80 provided about $71 \%$ and $63 \%$ of the compressive strength of the control mixture respectively.

\section{Electrical resistivity}

The results of the electrical resistivity of the mortars over the time of curing are presented in figure 4 . It can be easily recognised that incorporating both GGBS and MFA in this study improved the electrical resistivity of the produced binders and their mortars. This reflects an enhancing of the durability performance. Unlike what was obtained from the compressive strength, the electrical resistivity for all mortars contained GGBS and MFA increased with the increase of the GGBS and MFA content that replaced OPC for the mortars tested at all curing ages ( $3,7,14$ and 28 days) as shown in Fig. 4. The results also showed that the control binder (OPC) indicated an electrical resistivity similar to that of the T40 mixture only after 3 days of curing. For longer curing time, the ternary binders indicated electrical resistivity higher than that for the control binder.

This improvement in surface electrical resistivity of ternary mixtures lead to increase the resistant to chloride penetration compared to the control mortar [24, 31]. Thus, improved resistance of ternary blends mixes to the chloride penetration is mainly due to the incorporation of MFA and GGBS that lead to reduce diffusivity of chloride ions. This is due to the formation of a dense microstructure in the interfacial transition zone. It also increases the density and calcium silicate hydrate $(\mathrm{C}-\mathrm{S}-\mathrm{H})$ gel of the cement paste generated during cement hydration, which in turn significantly improves the strength and durability of the mortar, as observed by other authors [18, 24, 32].

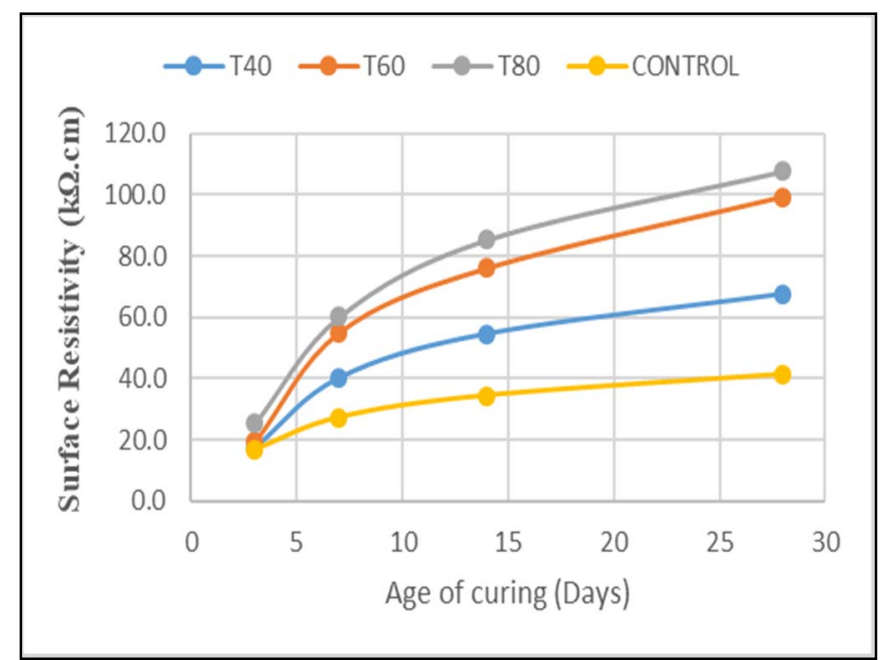

Fig. 4. Electrical resistivity of different ternary blends at different ages

According to the AASHTO T 358 [23] classification, both the control mixture and ternary mixtures T40 and T60 have showed moderate chloride ion penetrability while the ternary mixture T80 has showed low chloride ion penetrability after 3 days of curing. All the ternary mixtures have showed very low chloride ion penetrability at the age of 7 days onwards with a significant improvement in the electrical resistivity and increasing the GGBS and MFA content. On the other hand, the control mixture has showed low chloride ion penetrability after 7 to 14 days of curing and very low chloride ion penetrability at the age of 28 days. 


\section{CONCLUSION}

Based on the results obtained from the present study, we have drawn the following conclusions:

- The consistency of the new ternary mixtures contained MFA+GGBS varies between $33 \%$ and $35 \%$, depending on ground conditions of waste materials. Consistency of control mixture and ternary mixture T40 was found to be $33 \%$, while that of the ternary mixtures T60 and T 80 was found to have a consistency of $35 \%$.

- All the ternary mixtures tend to reduce the initial and final setting time of paste in comparison with control mixture. The setting time values are arranged from the highest to the lowest value as follows: control, T40, T60 and T80.

- All the ternary mortars mixtures containing MFA+GGBS exhibited a reduction in the compressive strength at all curing ages with increasing the replacement levels in comparison with the control mortar.

- At all curing ages, all the ternary mixtures have showed better electrical resistivity performance than the control mixture and the improvement in the electrical resistivity was proportional with increasing the GGBS and MFA content.

\section{ACKNOWLEDGMENTS}

The corresponding author would like to acknowledge the financial support of this research by the Faculty of Engineering and Technology at Liverpool John Moores University (LJMU).

\section{REFERENCES}

[1] Shubbar, A., H.M. Jafer, A. Dulaimi, W. Atherton, and A. Al-Rifaie, The Development of a Low Carbon Cementitious Material Produced from Cement, Ground Granulated Blast Furnace Slag and High Calcium Fly Ash. International Journal of Civil, Environmental, Structural, Construction and Architectural Engineering, 2017. 11(7): p. 905-908.

[2] Karim, M.R., M.F.M. Zain, M. Jamil, and F.C. Lai, Fabrication of a non-cement binder using slag, palm oil fuel ash and rice husk ash with sodium hydroxide. Construction and Building Materials, 2013. 49: p. 894-902.

[3] Specht, E., T. Redemann, and N. Lorenz, Simplified mathematical model for calculating global warming through anthropogenic CO2. International Journal of Thermal Sciences, 2016. 102: p. 1-8.

[4] Shubbar, A.A., M. Sadique, H.K. Shanbara, and K. Hashim, The Development of a New Low Carbon Binder for Construction as an Alternative to Cement, in Advances in Sustainable Construction Materials and Geotechnical Engineering. 2020, Springer. p. 205-213.

[5] Shubbar, A.A., A. Al-Shaer, R.S. AlKizwini, K. Hashim, H. Al Hawesah, and M. Sadique, Investigating the influence of cement replacement by high volume of GGBS and PFA on the mechanical performance of cement mortar, in International Conference on Civil and Environmental Engineering Technologies, Kufa University, Iraq, 23-24 April. 2019.

[6] Shubbar, A.A., M. Sadique, P. Kot, and W. Atherton, Future of claybased construction materials - A review. Construction and Building Materials, 2019. 210: p. 172-187.

[7] Zhang, X., J. Shen, Y. Wang, Y. Qi, W. Liao, W. Shui, L. Li, H. Qi, and $\mathrm{X}$. $\mathrm{Yu}, \mathrm{An}$ environmental sustainability assessment of China's cement industry based on emergy. Ecological Indicators, 2017. 72: p. 452-458.

[8] Al Hawesah, H., A. Shubbar, and R.L. Al Mufti. Non-destructive assessment of early age mortar containing stainless steel powder. in The 17th Annual International Conference on Asphalt, Pavement Engineering and Infrastructure 21st -22nd February. 2018. Liverpool, UK.
[9] van Ruijven, B.J., D.P. van Vuuren, W. Boskaljon, M.L. Neelis, D. Saygin, and M.K. Patel, Long-term model-based projections of energy use and $\mathrm{CO} 2$ emissions from the global steel and cement industries. Resources, Conservation and Recycling, 2016. 112: p. 1536.

[10] Aprianti, E., P. Shafigh, S. Bahri, and J.N. Farahani, Supplementary cementitious materials origin from agricultural wastes - A review. Construction and Building Materials, 2015. 74: p. 176-187.

[11] BS EN 196-1. Methods of testing cement-Part 1: Determination of strength. 2005, British Standard Inistitute: London

[12] Standard, B., Fly ash for concrete - Definitions, requirements and quality control. 1995.

[13] Ranjbar, N., M. Mehrali, A. Behnia, U.J. Alengaram, and M.Z. Jumaat, Compressive strength and microstructural analysis of fly ash/palm oil fuel ash based geopolymer mortar. Materials \& Design, 2014. 59: p. 532-539.

[14] European Committee for Standarization, BS EN 197-1:2000, Cement - Part 1: Composition, specifications and conformity criteria for common cements. 2000, British Standard Institution: London.

[15] Shubbar, A., W. Atherton, H.M. Jafer, A. Dulaimi, and D. AL-Faluji, The Development of a New Cementitious Material Produced from Cement and GGBS, in The 3rd BUiD Doctoral Research Conference, the British University in Dubai, . 2017: UAE.

[16] Celik, O., E. Damci, and S. Paskin, Characterisation of fly ash and its effect on the compressive strength properties of portland cement. Indian Journal of Engineering \& Materials Science 2008. 15(5): p. 433-440.

[17] Zhao, J., D. Wang, P. Yan, S. Zhao, and D. Zhang, Particle characteristics and hydration activity of ground granulated blast furnace slag powder containing industrial crude glycerol-based grinding aids. Construction and Building Materials, 2016. 104: p. 134-141.

[18] Shubbar, A.A., H. Jafer, A. Dulaimi, K. Hashim, W. Atherton, and M. Sadique, The development of a low carbon binder produced from the ternary blending of cement, ground granulated blast furnace slag and high calcium fly ash: An experimental and statistical approach. Construction and Building Materials, 2018. 187: p. 1051-1060.

[19] Naik, T.R., S.S. Singh, and B.W. Ramme. Time of setting influenced by inclusion of fly ash and chemical admixtures. in in The 7th International Conference on Fly Ash, Silica Fume, Slag and Natural Pozzolans in Concrete (CANMET/ACI). 2001. Madras, India: The 7th International Conference on Fly Ash, Silica Fume, Slag and Natural Pozzolans in Concrete (CANMET/ACI).

[20] British Standard Institution, Method of testing cement. Determination of setting time and soundness, BS EN 196-3 and A1. 2008, British Standard Institution.: London

[21] BSI, Methods of testing cement-Part 1: Determination of strength. 2005, British Standard Inistitute: London.

[22] Afroughsabet, V. and T. Ozbakkaloglu, Mechanical and durability properties of high-strength concrete containing steel and polypropylene fibers. Construction and Building Materials, 2015. 94: p. 73-82.

[23] AASHTO T 358, Standard Method of Test for Surface Resistivity Indication of Concrete's Ability to Resist Chloride Ion Penetration. 2017, American Association of State and Highway Transportation Officials.: Washington DC.

[24] Zahedi, M., A.A. Ramezanianpour, and A.M. Ramezanianpour, Evaluation of the mechanical properties and durability of cement mortars containing nanosilica and rice husk ash under chloride ion penetration. Construction and Building Materials, 2015. 78: p. 354361 .

[25] Dave, N., Misra, A. K., Srivastava, A. \& Kaushik, S. K., Experimental analysis of strength and durability properties of quaternary cement binder and mortar. Construction and Building Materials, 2016. 107: p. 117-124.

[26] Sadique, M., H. Al-Nageim, W. Atherton, L. Seton, and N. Dempster, Mechano-chemical activation of high-Ca fly ash by cement free blending and gypsum aided grinding. Construction and Building Materials, 2013. 43: p. 480-489.

[27] Dave, N., A.K. Misra, A. Srivastava, and S.K. Kaushik, Experimental analysis of strength and durability properties of quaternary cement binder and mortar. Construction and Building Materials, 2016. 107: p. 117-124. 
[28] Salih, M.A., N. Farzadnia, A.A. Abang Ali, and R. Demirboga, Development of high strength alkali activated binder using palm oil fuel ash and GGBS at ambient temperature. Construction and Building Materials, 2015. 93: p. 289-300.

[29] Limbachiya, V., E. Ganjian, and P. Claisse, Strength, durability and leaching properties of concrete paving blocks incorporating GGBS and SF. Construction and Building Materials, 2016. 113: p. 273-279.

[30] Attari, A., C. McNally, and M.G. Richardson, A probabilistic assessment of the influence of age factor on the service life of concretes with limestone cement/GGBS binders. Construction and Building Materials, 2016. 111: p. 488-494.
[31] Layssi, H., P. Ghods, A. Aali R. , and M. Salehi, Electrical Resistivity of Concrete, Concepts, applications, and measurement techniques. 2015, Concrete International.

[32] Hawileh, R.A., J.A. Abdalla, F. Fardmanesh, P. Shahsana, and A. Khalili, Performance of reinforced concrete beams cast with different percentages of GGBS replacement to cement. Archives of Civil and Mechanical Engineering, 2017. 17(3): p. 511-519. 